LOS DESAFÍOS DE INCLUIR LAS PERSPECTIVAS LOCALES $Y$ REGIONALES EN LA ENSEÑANZA DE UNA HISTORIA ARGENTINA MÁS COMPLEJA

DOI: $10.5935 / 2177-6644.20190011$

\author{
OS DESAFIOS DE INCLUIR \\ PERSPECTIVAS LOCAIS E \\ REGIONAIS NO ENSINO DE UMA \\ HISTÓRIA ARGENTINA MAIS \\ COMPLEXA \\ THE CHALLENGES OF INCLUDING \\ LOCAL AND REGIONAL \\ PERSPECTIVES IN TEACHING A \\ MORE COMPLEX ARGENTINE \\ HISTORY
}

Susana Bandieri *

\begin{abstract}
Resumen: Si observamos la mayoría de las producciones historiográficas que pretenden cubrir de manera más general la denominada "Historia Nacional Argentina", especialmente en los manuales escolares y en las obras de divulgación general, y más acentuadamente aún si prestamos atención a los mapas que nos provee el sistema educativo para enseñar en las aulas, rápidamente observamos el peso que todavía tiene una visión centralizada y homogénea de los procesos históricos. Desde esa perspectiva, la "historia nacional" se recluye dentro de los límites de la soberanía territorial del Estado, mientras que el desarrollo de la pampa húmeda y del modelo agroexportador, con clara vocación atlántica, se sobreponen a la incorporación de las particularidades de otras regiones del interior del país, en especial de aquellas más periféricas y marginales a tal modelo. En este artículo pretendemos, con especial atención a las investigaciones de la autora sobre el espacio patagónico, destacar la necesidad de incorporar las producciones historiográficas en perspectiva local y regional como una manera de complejizar estas visiones generalizantes de la historia nacional argentina e incorporarlas a los procesos de enseñanza, particularmente en los niveles no universitarios.
\end{abstract}

Palabras clave: Historia Loca. Enseñanza. Complejidad.

Resumo: Se observarmos a maioria das produções historiográficas que buscam abordar de maneira mais geral a chamada "História Nacional da Argentina", especialmente nos livros escolares e obras de divulgação geral, e ainda mais se prestarmos atenção aos mapas fornecidos pelo sistema educacional para ensinar nas salas de aula, rapidamente observamos o peso que ainda tem uma visão centralizada e homogênea dos processos históricos. Nessa perspectiva, a "história nacional" está confinada aos limites da soberania territorial do Estado, enquanto o desenvolvimento da pampa úmida e do modelo agroexportador, com clara vocação atlântica, sobrepõe-se à incorporação das particularidades de outras regiões do interior do país, especialmente aquelas que são mais periféricas e marginais a tal modelo. Neste artigo pretendemos, com especial atenção à pesquisa da autora sobre o espaço da Patagônia, destacar a necessidade de incorporar produções historiográficas na perspectiva local e regional como forma de tornar mais complexas essas visões generalizadoras da história nacional da Argentina e incorporá-las aos processos de ensino, particularmente a nível não universitário.

Palavras-chave: História Local. Ensino. Complexidade.

Abstract: If we observe the majority of the historiographic productions whichpursue to cover in a more extensive way the so-called "Argentine National History", especially in school textbooks and general

\footnotetext{
${ }^{*}$ Dra. en Historia, Profesora Consulta de la Universidad Nacional del Comahue (UNCo), Neuquén, Argentina. Investigadora del CONICET en el IPEHCS - Instituto Patagónico de Estudios de Humanidades y Ciencias Sociales - (CONICET/UNCo.) E-mail: susana.bandieri@gmail.com
} 
dissemination works, and even more so if we pay attention to the maps provided by the educational system to teach in the classrooms, we quickly observe the importance that still has a centralized and homogenous vision of the historical processes. From this perspective, the "national history" is confined within the limits of the territorial sovereignty of the State, while the development of the humid pampa and the agro-export model, with a clear Atlantic vocation, overlap the incorporation of the particularities of other regions of the interior of the country, especially those that are more peripheral and marginal to such a model. In this article we intend, with special attention to the author's research on the Patagonian space, highlight the need to incorporate historiographic productions in local and regional perspective as a way to make these generalizing visions of Argentina's national history more complex and incorporate them into the processes of teaching, particularly at non-university levels.

Keywords: Local History. Teaching. Complexity.

\section{A manera de introducción}

Como sosteníamos en una artículo reciente (BANDIERI, 2018a), si observamos la mayoría de las producciones historiográficas que pretenden cubrir de manera más general la denominada "Historia Nacional Argentina", especialmente en los manuales escolares y en las obras de divulgación general, y más acentuadamente aún si prestamos atención a los mapas que nos provee el sistema educativo para enseñar en las aulas, rápidamente observamos el peso que todavía tiene una visión centralizada y homogénea de los procesos históricos. Desde esa perspectiva, la "historia nacional" se recluye dentro de los límites de la soberanía territorial del Estado, mientras que el desarrollo de la pampa húmeda y del modelo agroexportador, con clara vocación atlántica, se sobreponen a la incorporación de las particularidades de otras regiones del interior del país, en especial de aquellas más periféricas y marginales a tal modelo. Esta cuestión, muy visible en los análisis socio-económicos, se repite también en las interpretaciones de fenómenos específicos de la provincia de Buenos Aires, como pueden ser "el rosismo"proceso en el que el gobernador de esa provincia, Juan Manuel de Rosas, preside la Confederación de provincias argentinas en las décadas de 1830 y 40- cuyas particularidades se extienden al conjunto nacional; o, en etapas más recientes, "el peronismo", en sus distintos gobiernos, como una expresión política única que desconoce sus distintas particularidades provinciales (FERNÁNDEZ, 2009, p. 36-37).

Del mismo modo, las llamadas "fronteras internas" entre las comunidades indígenas e hispano-criollas, particularmente a lo largo de los siglos XVIII y XIX, parecen actuar - pese a la variada y completa producción académica de que se dispone en sentido inverso-, como verdaderas vallas para la circulación de bienes y personas, lo cual implica que zonas como la propia -en este caso la Patagonia- sigan apareciendo como 
espacios vacíos o, lo que es lo mismo, "desiertos". La historia de las comunidades indígenas suele ser el capítulo inicial de la "historia nacional" hasta las llamadas "campañas al desierto" producidas entre los años 1879 y 1885, desconociendo la activa participación de los pueblos originarios como actores políticos, económicos y sociales hasta la actualidad.

Es decir, se sigue repitiendo, en muchos casos, una historia que no supera los viejos esquemas interpretativos, mientras que los límites territoriales del Estado-Nación, consolidado hacia 1880 parecen interrumpir todo tipo de contacto con los países vecinos, produciendo una evidente tensión entre las visiones generalizadoras de la denominada "historia nacional" y las situaciones heterogéneas y variadas de los espacios que la integran, en gran parte vinculados entre sí y con los territorios fronterizos. Evidentemente, esto no es otra cosa que una derivación, y por cierto notable supervivencia, de los trabajos que retomaban, desde otra vertiente conceptual, los estudios que en épocas más pretéritas acentuaban el énfasis en el Estado nacional y en sus etapas de consolidación, aunque cada vez más se coincide en la necesidad de incorporar otras miradas y elaborar nuevas síntesis sobre la base de incluir una importante y densa producción historiográfica construida en clave local y regional que, lejos de marginar la perspectiva nacional, la incorpora y complejiza a partir de las pluralidades de los espacios y de las temporalidades (BANDIERI y FERNÁNDEZ, 2017).

Es decir, si bien hay una densa y cada vez más importante producción historiográfica desde y sobre las distintas regiones argentinas, la misma no necesariamente se refleja en las currículas de los planes de estudio ni en las producciones que circulan a nivel nacional $\mathrm{y}$, mucho menos, en los manuales de enseñanza no universitaria o en las obras de divulgación. ${ }^{1}$ A los efectos de evitar omisiones involuntarias o interpretaciones erróneas que pudieran no estar reflejando cabalmente el pensamiento de los autores, usaremos como ejemplo nuestra propia producción.

\section{Producir historia desde y sobre la Patagonia argentina}

En nuestro caso en particular, las razones de la inclinación temprana por los estudios históricos desde una perspectiva regional tuvieron motivaciones variadas, que

\footnotetext{
${ }^{1}$ A este respecto, ver especialmente el detallado artículo de Sandra Fernández (2009).
} 
seguramente se iniciaron en relación con el fuerte contenido en ese sentido que caracteriza a la Universidad Nacional del Comahue (UNCo.) -con sede central en la ciudad de Neuquén y delegaciones en el conjunto norpatagónico-, de la cual la autora es egresada y donde ha desarrollado toda su carrera docente y de investigación. Esto planteaba del vamos un necesario compromiso con la obligación de dar respuesta a los requerimientos de la sociedad que la contiene. Por otra parte, la existencia de fuentes documentales -al menos de algunas- y de informantes calificados en la zona facilitaba la producción de conocimiento histórico regional.

Pero también actuó el convencimiento de la necesidad de aportar investigaciones nuevas que, desde distintos ámbitos del país, contribuyeran a complejizar una historia nacional demasiado generalizante, que repetía los vicios característicos del proceso de consolidación del Estado nacional y del modelo económico dominante, desconociendo las especificidades de los procesos históricos de espacios periféricos a ese modelo, particularmente en las últimas décadas del siglo XIX y primeras del XX, período al que la autora dedicaba, por otra parte, sus tareas docentes en la Universidad.

Creemos también, en este mismo sentido, que el macro crecimiento de los centros académicos de primer nivel en el área pampeana coadyuvó a este proceso de construcción historiográfica, así como lo hizo la carencia o escasez de los mismos en otras áreas, situación que se ha revertido notablemente en los últimas décadas, lo cual guarda directa relación con el impulso alcanzado por las perspectivas históricas locales y regionales que hoy se desarrollan en diversas universidades e institutos de investigación del interior del país.

El hecho de estudiar, además, procesos socio-económicos en áreas andinas mediterráneas, sirvió también para afirmar la idea de que era preciso desmitificar viejas creencias con respecto a que la unificación política que acompañó al proceso de consolidación del Estado nacional argentino había derivado, como consecuencia inmediata, en la unificación económica plena del país en el último cuarto del siglo XIX y, en concordancia con ello, que la ocupación económica y social de la Patagonia habría tenido una orientación exclusivamente atlántica.

Pero debe necesariamente reconocerse que, cuando comenzamos a realizar investigación histórica regional de manera más sistemática, allá por mediados de la década de 1980, después de la apertura democrática del país, también lo hacíamos imbuidos de algunos preconceptos sólidamente instalados en la historiografía local y 
muchas veces incorporados en la documentación oficial. Partíamos, en principio, de hacer una historia de Neuquén encerrada en los límites del antiguo Territorio Nacional, luego Provincia de igual nombre. Aunque no desconocíamos los importantes vínculos socioeconómicos existentes entre las comunidades indígenas y las hispano-criollas que articulaban ambas márgenes de la cordillera de los Andes antes de que los Estados nacionales -Argentina y Chile- se definieran como tales, entendíamos que la llegada del ferrocarril al vértice oriental del territorio y el consecuente cambio de la capital desde Chos Malal, en el norte neuquino, a ese punto, en el año 1904, había reorientado definitivamente el funcionamiento socio-económico de la región hacia el Atlántico. La misma documentación oficial así parecía indicarlo. ${ }^{2}$ Con el avance de nuestras investigaciones pronto descubrimos que el centro socio económico regional, pese a los deseos del gobierno nacional, seguía estando en las áreas andinas, lo cual era fácilmente comprobable en diversas fuentes documentales de carácter cuantitativo y cualitativo.

Para la correcta interpretación del tema, incluimos a continuación un mapa de la actual provincia de Neuquén que muestra la ubicación geográfica de ambas capitales y su dilatada área fronteriza con el territorio chileno a través de la cordillera de los Andes:

\footnotetext{
${ }^{2}$ El entonces Ministro del Interior, Joaquín V. González, justificaba de esta manera la medida: “... me ha traído al convencimiento de que la capital del Neuquén debe levantarse en el amplio valle que comienza al pasar el río. Si bien es cierto que esta posición no es materialmente central con respecto al territorio, es en cambio de alta significación económica y política, primero porque consulta los agentes más poderosos de civilización actual y segundo porque en vez de impulsar el comercio de adentro hacia afuera, como sucede hoy, lo incluirá fuertemente de afuera para adentro, siguiendo las corrientes centrípetas auxiliadas por vías férreas y fluviales que concurren al Atlántico con su gran puerto de Bahía Blanca..." (Archivo Histórico Provincial, Neuquén, Libro Copiador T/1904, Telegrama del Ministro del Interior al Gobernador de Neuquén, Carlos Bouquet Roldán, 7-4-1904).
} 


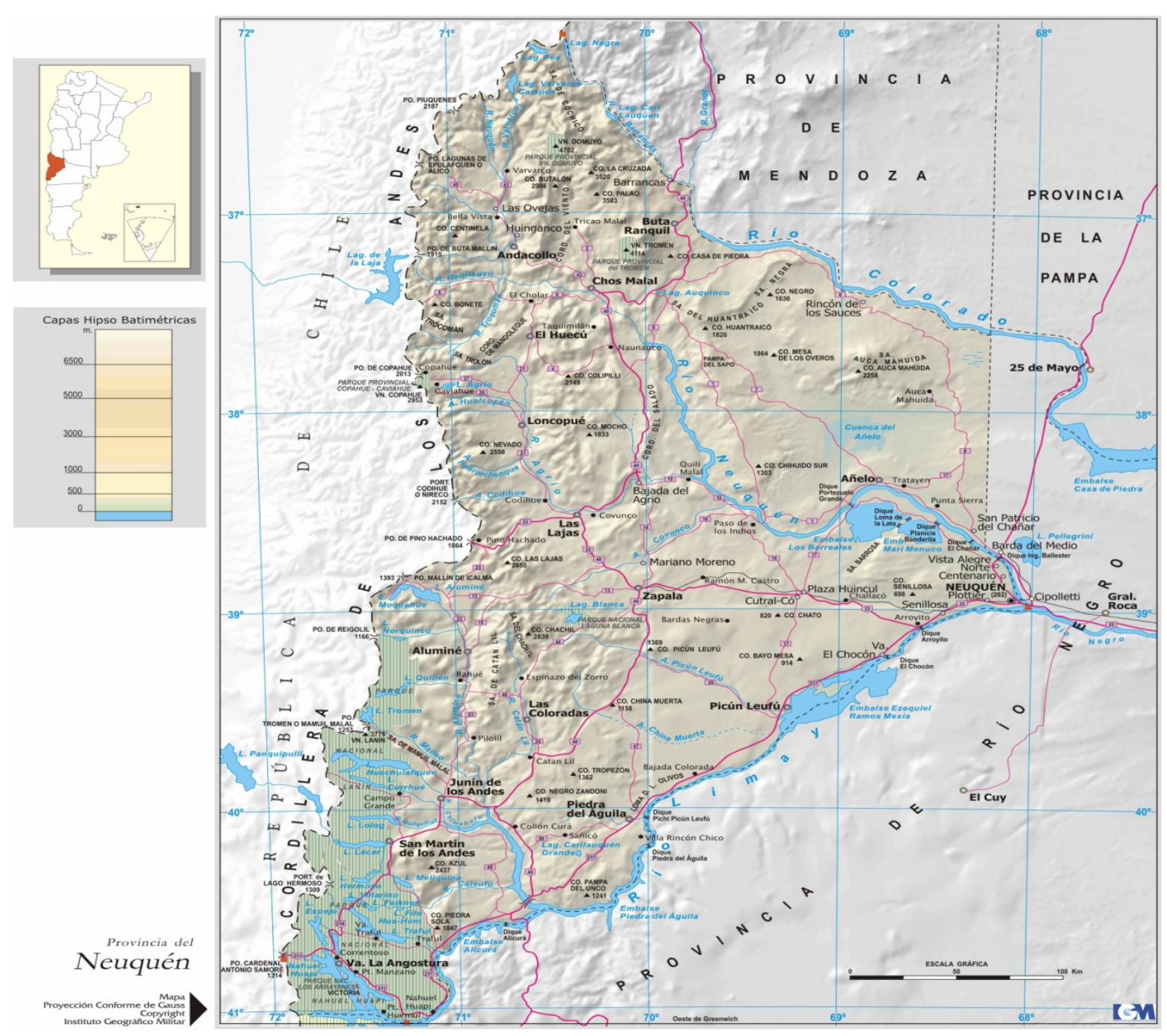

Fuente: http://mapoteca.educ.ar/.files/index.html.1.17.html

Optamos entonces por estudiar las relaciones socioeconómicas producidas alrededor de las actividades dominantes en el territorio -en principio la ganadería-, reconstruyendo las formas de producción, transformación, comercialización y consumo, y desprendiendo de ellas la conformación de estructuras políticas y sociales que, en última instancia, nos sirvieran para definir en cada tiempo y para cada objeto de estudio un determinado espacio regional. En ese sentido, los indicadores más importantes fueron aquellos que nos permitieron identificar a los sujetos sociales intervinientes y sus diversas interacciones a uno y otro lado de los Andes.

Esto nos demandó, en primer término, trabajar en la reconstrucción de los circuitos mercantiles y de los lazos socio-económicos entra ambas márgenes de la cordillera, lo cual permitió comprobar la supervivencia de las antiguas formas indígenas de comercialización del ganado regional en el mercado chileno. En un claro ejemplo de 
economías complementarias, mientras el área de cría se encontraba en el oriente cordillerano, la transformación, el consumo y la comercialización se efectuaban en las ciudades y puertos del Pacífico sur. Por supuesto que la llegada del ferrocarril a la nueva capital de Neuquén en el extremo más oriental del territorio a principios del siglo XX, había introducido cambios, pero estos no habían afectado en demasía el funcionamiento tradicional de las áreas andinas. La pregunta era entonces ¿hasta cuándo habían durado estas formas tradicionales del funcionamiento socioeconómico regional?

Futuros avances en la investigación indicaron que recién en la segunda mitad de la década de 1920 y, particularmente, a partir de los años 1930 y 40, ambos Estados, argentino y chileno, habían comenzado a tomar medidas arancelarias y a colocar límites y controles al comercio cordillerano de ganado, el cual se habría cortado definitivamente, al menos en términos legales, en la segunda posguerra. La hipótesis que entonces manejamos era que la crisis del modelo agroexportador y la profundización de la etapa sustitutiva de importaciones producidas en esos años había necesitado de mercados nacionales más firmemente controlados. Pronto descubrimos que esta nueva periodización, que resultaba válida para la Patagonia, también lo era para otras áreas andinas del país productoras de ganado, marginales y periféricas al modelo agroexportador, tal y como pudo demostrarse con la publicación de una serie importante de trabajos de colegas argentinos y chilenos que investigaban el tema a lo largo de los Andes Meridionales, desde Jujuy y Antofagasta hasta Punta Arenas y Ushuaia, que oportunamente coordinamos (BANDIERI, 2001).

La verdadera integración al mercado nacional de estas regiones habría sido entonces producto de un proceso muy largo y complejo, especialmente para los sectores de escasos recursos que antiguamente comercializaban sus animales en pie en el mercado trasandino, y no se había producido en el último cuarto del siglo XIX sino en la primera mitad del siglo XX. Más adelante demostramos que esta periodización no solo era válida en términos económicos, sino que también era aplicable a una serie muy importante de factores vinculados a la preocupación por "argentinizar" la Patagonia, cuestión por cierto no ajena a las huelgas de los obreros rurales santacruceños de la década de 1920 exageradamente atribuidas a la presencia de trabajadores chilenos con ideologías revolucionarias-, y a la intencionalidad de los grupos nacionalistas que a partir de 1930 dominaron la política nacional argentina. De esa manera, una serie de instituciones y agentes estatales se hicieron presentes en la Patagonia a partir de esos años 
(Gendarmería, Vialidad Nacional, Parques Nacionales, escuelas de frontera, sucursales del Banco de la Nación Argentina, Yacimientos Petrolíferos Fiscales -YPF-, Yacimientos Carboníferos Fiscales -YCF-, medios radiales nacionales, etc.) consolidando una presencia estatal hasta entonces relativamente débil (BANDIERI, 2009; 2018c).

En el caso de la Patagonia entonces, los resultados de las investigaciones regionales indicaban la necesidad de considerar una nueva periodización para una presencia estatal más definitiva que no se correspondía con los años 1880, como sostenía en general la historiografía para el conjunto nacional, sino con las décadas de 1930 y 40, cuando los gobiernos de turno realmente se preocuparon por incorporar de manera más efectiva a la soberanía nacional a los territorios del sur, lo cual también puede relacionarse con el otorgamiento del voto a sus habitantes a mediados de la década de 1950. ${ }^{3}$ Asimismo, se imponía una nueva espacialización regional de las relaciones socioeconómicas, no sujeta a los límites políticos nacionales y/o territoriales, que necesariamente debía incorporar a la frontera andina como un espacio social construido históricamente, de gran dinamismo y alta complejidad (BANDIERI, 2013a). Estos resultados, cuestionadores de las temporalidades y de la perdurabilidad de los contactos fronterizos, desconocidos por la historiografía nacional, exigieron también diversas aproximaciones a las bases conceptuales y metodológicas en que se apoyaban nuestras investigaciones, ${ }^{4}$ así como a los resultados empíricos de ellas derivados.

En resumen, hacer historia socioeconómica de Neuquén, tanto en sus etapas de Territorio Nacional como de Provincia, no alcanzaba por sí misma para aproximarnos comprensivamente a nuestro objeto de estudio. Las variables espacio-temporales se habían modificado sustancialmente a partir de la investigación regional, lo cual derivaba en la preocupación por publicar estos resultados para su eventual incorporación en la historia argentina y, como derivación especialmente buscada, en el campo de la enseñanza de la historia. Cruzando la Cordillera... La frontera argentino-chilena como espacio social (BANDIERI, 2001) ${ }^{5}$ fue el primer producto de los investigadores y becarios del

\footnotetext{
3 Cabe recordar que los espacios patagónicos expropiados a las comunidades indígenas por las armas y el exterminio entre 1879 y 1885 , fueron incorporados a la soberanía nacional en condiciones muy diferentes a las de las tradicionales provincias argentinas. Bajo la denominación de Territorios Nacionales, sus autoridades eran elegidas desde el gobierno nacional que también administraba sus rentas. En consecuencia, sus habitantes no fueron ciudadanos plenos de la nación hasta la provincialización de los mismos, producida recién a mediados de la década de 1950, lo cual les permitió ejercer el derecho a voto a nivel nacional.

${ }^{4}$ Sobre este tema, ver la publicación de la autora en esta misma revista (BANDIERI, 2018b).

${ }^{5}$ Editado por la Universidad Nacional del Comahue en 2001, reeditado en 2006 y actualmente en prensa en su tercera edición en la Universidad de Los Lagos de Chile, este libro inauguró la Serie Publicaciones del CEHIR.
} 
Centro de Estudios de Historia Regional -CEHIR- de la Universidad Nacional del Comahue que investigaban estos temas. ${ }^{6}$ Hecho en Patagonia. La historia en perspectiva regional (BANDIERI, BLANCO, VARELA, 2006) ${ }^{7}$ fue el segundo, aunque ambos todavía dedicados al mundo académico universitario.

\section{Enseñar Historia Argentina en la Patagonia}

Aún cuando las investigaciones realizadas desde la Patagonia han sido tomadas como referencias conceptuales y metodológicas, sumadas a las de otros colegas que han realizado muy exitosamente esfuerzos similares, ${ }^{8}$ por quienes desarrollan investigaciones en diversos centros académicos del interior del país, el tema de la creación de conocimientos producida desde estos centros, por cierto numerosa y muy sólida, no está necesariamente incluida, según adelantáramos, en la historiografía nacional y, mucho menos aún, en los manuales escolares destinados a otros niveles de enseñanza ni en las obras de divulgación (FERNÁNDEZ, 2009). En definitiva, el tema está instalado, pero todavía resta mucho por hacer.

En una oportunidad no muy lejana se me pidió disertar en unas importantes jornadas patagónicas que se efectúan cada dos años de manera consecutiva y sistemática. ${ }^{9}$ El título de la disertación, pensado por los organizadores del evento, era "La Patagonia tiene quien le escriba". Yo titulé a mi conferencia "La Patagonia tiene quien le

La idea era reunir estudios sobre el funcionamiento de la frontera argentino-chilena como espacio social, mostrando la complejidad de un fenómeno de larga duración y significativa presencia en los espacios andinos, para discutir y comparar las características de tal funcionamiento en distintos espacios regionales argentinos y chilenos que compartieron una problemática histórica común. Para ello se convocó a un grupo importante de colegas de ambas nacionalidades que contribuyeron con sus investigaciones en las distintas secciones en que se dividió la estructura general de la obra.

${ }^{6}$ El CEHIR fue creado en la Facultad de Humanidades de la UNCo. en 1995, del cual la autora fuera fundadora y directora hasta el año 2016, hoy bajo la conducción de la Dra. Graciela Blanco. Si bien en este artículo se hace casi exclusiva mención a la producción de quien escribe, por razones de espacio y conocimiento empírico, cabe destacar que en el CEHIR se incorporaron una serie muy importante de investigadores y becarios cuyos aportes a la creación de conocimientos son hoy ampliamente reconocidos. Otros centros de investigación creados casi simultáneamente en la Facultad de Humanidades de la misma Universidad, también aportaron y aportan a la construcción de las temáticas regionales desde la Historia Social (GEHISO -Grupo de Estudios de Historia Social-), dirigido por el Dr., Enrique Mases, y desde la Historia Política (CEHEPYC -Centro de Estudios Históricos de Estado, Política y Cultura-), bajo la dirección de la Dra. Orietta Favaro.

7 Esta obra fue el resultado de un Programa de Investigación, aprobado y financiado por la Secretaría de Investigación de la UNCo., donde se reunieron los trabajos de una cantidad importante de profesionales con larga trayectoria en la investigación regional, pertenecientes a distintas instituciones y centros académicos ubicados en la Patagonia.

${ }^{8}$ Ver, como ejemplos, los importantes trabajos incluidos en Fernández y Dalla Corte (2001) y Fernández (2007).

9 Panel "La Patagonia tiene quien le escriba", coordinado por la Dra. Laura Méndez con moderación de Raúl Mandrini, en el IX Congreso de Historia Social y Política de la Patagonia Argentino-Chilena, Trevelin, Chubut, Argentina, octubre de 2011. 
escriba ipero tiene quien la lea?". Porque, efectivamente, creo que gran parte del problema que mencionamos anteriormente tiene que ver con el hecho de que falta profundizar, por parte de quienes cultivamos el oficio, las lecturas de los trabajos que se producen en el conjunto nacional. Es cierto que son muchos y variados, pero sólo así podremos lograr visiones más complejas y heterogéneas de la historia argentina.

Por cierto, cabe mencionar que la mayoría de las universidades del interior del país, incluida la propia, ${ }^{10}$ tienen incorporados en sus estructuras curriculares diversos Seminarios de Historia Regional, con lo cual podemos sostener que, al menos, la historia de las regiones en que cada uno de esos centros se encuentra localizado se enseña y se conoce por los futuros profesores de la disciplina.

Sin embargo, existen todavía varias inconsistencias: muchas veces, la historia de la región se limita a la historia de la propia provincia sin vinculaciones explícitas con la historia nacional. ${ }^{11} \mathrm{Ha}$ costado mucho y sigue costando aún entender que las investigaciones sobre determinadas áreas del país no requieren de una delimitación territorial previa, sino que el espacio en que se producen los procesos históricos son solo una variable más que permite entender más cabalmente lo que se pretende investigar, lo cual obliga, más que frecuentemente, a superar no solo límites locales y provinciales, sino también internacionales. ${ }^{12}$ Otra carencia sentida es la falta de estudios comparativos e interdisciplinarios entre diversas investigaciones regionales. Tema no menor porque impide los avances hacia síntesis más abarcativas que las que la propia región incluye.

Pero la limitación más seria sigue siendo la falta de incorporación de los avances regionales en algunas versiones "nacionales" supuestamente mas abarcativas que siguen encerrando la historia en los límites del Estado nación, como también lo muestran los

\footnotetext{
10 Aunque, de manera curiosa y contradictoria, dado el avance antes mencionado en las investigaciones de carácter regional en la UNCo., la carrera de Profesorado y Licenciatura en Historia, cuyo plan de estudios no ha logrado reformarse todavía pese a su antigüedad (1885) tiene un Seminario de Historia Regional optativo, lo cual obliga a los docentes a volcar los resultados de sus investigaciones en cátedras menos específicas pero obligatorias como las Historias Argentinas o Americanas, por ejemplo.

11 En la Argentina, al contrario de otros países de América Latina, estuvo siempre más instalada la noción, aunque creemos que en la actualidad ya existe un cambio muy importante es ese sentido, de que la historia regional es un género menor, que guarda directa relación con las historias provinciales o, a lo sumo, con aquellas regiones tradicionales en que geográficamente se divide al país, como nordeste argentino (NEA), noroeste argentino (NOA) o la misma Patagonia, por ejemplo.

12 Ya Carlos Sempat Assadourian (1982), en sus estudios sobre la etapa colonial, planteaba tempranamente la necesidad de recuperar la noción de espacio socioeconómico frente a las limitaciones que ofrecían para el análisis empírico los recortes territoriales, basados tanto en los espacios nacionales como en los locales, unos por demasiado homogeneizadores y otros por excesivamente pequeños. Los espacios económicos debían reconstruirse en la investigación histórica atendiendo a un sistema de relaciones internas y externas que se modificarían en cada período, uno de cuyos elementos sobresalientes era la circulación de mercancías, pero también lo eran el estudio de las relaciones políticas, económicas, sociales y culturales (BANDIERI, 2013b).
} 
mapas que ilustran los contenidos, como luego se verá. La otra dificultad, no menos importante, es que esa visión se reproduce, amplificada, en los manuales destinados a la enseñanza de la historia argentina en los niveles educativos no universitarios y en conocidas obras de divulgación general, donde el interior del país prácticamente desparece de la explicación de los procesos históricos y lo que sucede en Buenos Aires y en la pampa húmeda se extiende al conjunto nacional. Entonces, el problema es: ¿cómo volcar el conocimiento creado desde y sobre la historia regional en la enseñanza, cuando prácticamente la totalidad de los manuales escolares destinados a los niveles primarios y secundarios siguen repitiendo las viejas formas de ver y hacer historia argentina? ${ }^{13}$

En nuestra región, al menos en la norpatagonia, esta último problema está, al menos parcialmente, cubierto, al igual que en muchas otras provincias argentinas. Miembros investigadores del CEHIR, en distintos momentos de su devenir institucional, destinaron buena parte de sus esfuerzos a trasladar lo que se investigaba a trabajos de lectura comprensiva para niños y jóvenes del sistema de enseñanza primaria y secundaria, de amplísima difusión (BLANCO, GENTILE y QUINTAR, 1998; WINDERBAUM, 1999, 2004, 2006, 2015, 2018; MÉNDEZ y IWANOW, 2001; MÉNDEZ, 2005; MÉNDEZ y DÍAZ, 2007; BANDIERI y BLANCO, 2007). Pero este esfuerzo no necesariamente está generalizado en el conjunto nacional, mostrando una carencia que, necesariamente, también habría que modificar por parte de aquellos académicos que solo escriben para la "academia".

\section{La perdurabilidad de los mitos en la Historia Nacional Argentina}

No obstante los avances antes mencionados, todavía quedan varios mitos importantes por destruir en la historia nacional argentina. Veamos algunos referidos específicamente a la Patagonia:

La percepción de un continente estéril, tal y como lo describiera Darwin, el naturalista inglés que acompañó a Fitz Roy en alguna de sus reiteradas incursiones por los mares australes, se instaló en el imaginario de la época y, curiosamente, perduró y perdura, no pocas veces, toda vez que se vincula a la Patagonia con la idea de "desierto". Campañas al "desierto" se llamaron, y todavía se llaman en muchos manuales escolares, las guerras de conquista y exterminio que el Estado argentino realizó sobre estos

\footnotetext{
${ }^{13}$ Importantes reflexiones sobre este tema pueden verse en Fernández (2009).
} 
territorios en la segunda mitad del siglo XIX, hasta entonces ocupados por las sociedades indígenas. Un "desierto" que, cabe aclararlo, no se pensaba como vacío de pobladores sino como "vacío de civilización". Esta es una primera idea a desterrar cuando se enseña historia argentina en nuestras escuelas y universidades. Todavía hoy debemos usar en las aulas mapas que repiten la idea de "espacios vacios", en tanto claro ejemplo de lo que venimos sosteniendo. Veamos algunos ejemplos:

El mapa que veremos a continuación representa los circuitos mercantiles de la era colonial y se incluye todavía en diversos atlas y obras históricas nacionales. Aquí pueden verse claramente dos cosas, los escasísimos vínculos del espacio rioplatense con el conjunto colonial, como por ejemplo con el territorio chileno, la Banda Oriental, el sur brasileño, entre otros, y dos espacios grisados, claramente delimitados como "territorios indígenas", que no guardan relación alguna con el conjunto espacial representado. Es decir, persiste aún la idea del territorio indígena como "espacio vacío". A eso se une, como ya adelantáramos, la invisibilización de estos actores como participantes activos en los procesos políticos y económico-sociales que simultáneamente se iban produciendo en el Río de la Plata en la etapa colonial y poscolonial. 


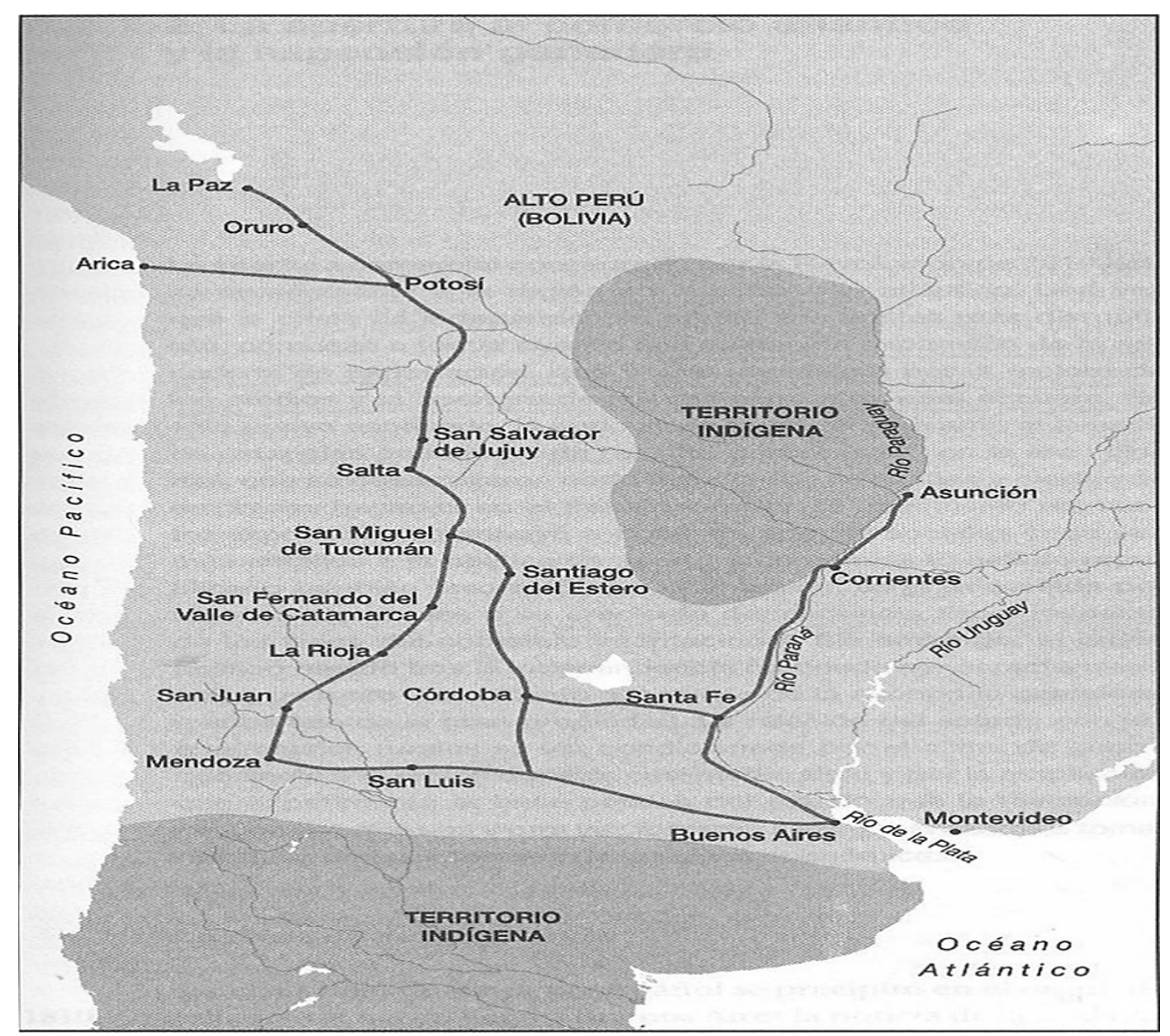

Fuente: reproducción del mapa que se utiliza frecuentemente en las aulas para desarrollar el tema.

En la imagen siguiente, que representa las rutas comerciales luego de los procesos de independencia, se insiste en la misma idea para la primera mitad del siglo Siglo XIX. Sólo dos vinculaciones visibles se marcan entre los espacios chileno y argentino, mientras que ninguno se reconoce entre las áreas indígenas y el resto del territorio, ni entre esas comunidades y los espacios vecinos, no obstante haber una frondosísima producción desde la Arqueología, la Antropología y la Historia que demuestran lo contrario, extendiéndolo incluso a épocas muy remotas. 


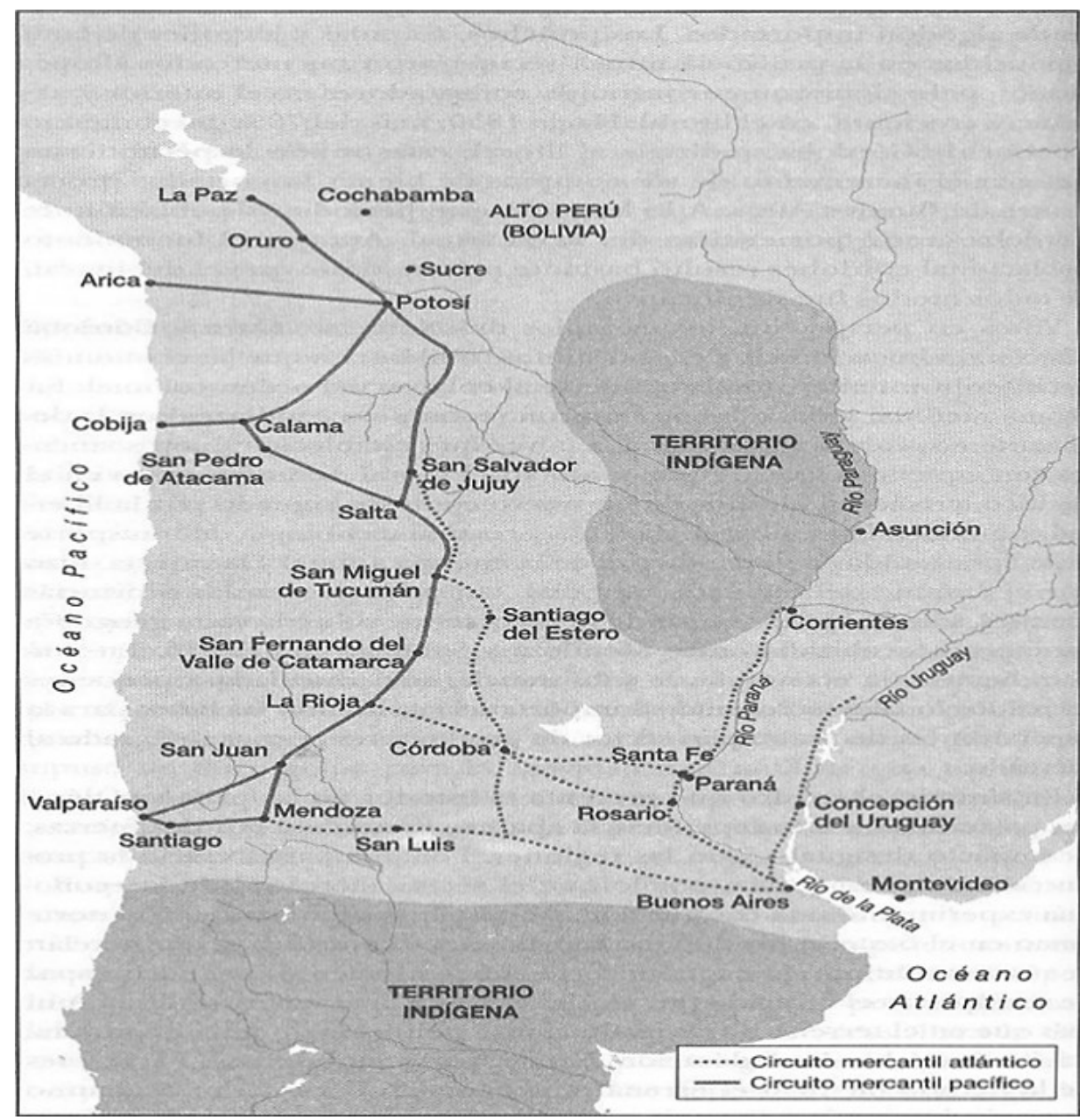

Fuente: reproducción del mapa que se utiliza frecuentemente en las aulas para desarrollar el tema. Puede verse también en diversos portales provinciales.

La imagen del mapa de la Argentina en el último cuarto del siglo XIX que se incluye a continuación, y se repite hasta la actualidad en numerosas publicaciones universitarias y no universitarias, muestra un país totalmente homogéneo y unificado hacia los años 1880. En este caso, se extienden al conjunto nacional las características de la zona más favorecida por el modelo agroexportador, desprendiendo de ello la conformación plena de un mercado nacional hacia fines del siglo XIX, en tanto se muestran absolutamente cortados los vínculos con los países limítrofes. De la estructuración de las comunicaciones ferroviarias que muestra este mapa, absolutamente funcional al modelo agrario orientado hacia el Atlántico, se desprende la unificación económica de la Argentina y el corte definitivo de los contactos con las áreas fronterizas. La unificación política del país resultaría entonces acorde, en tiempo y espacio, con la unificación económica del mismo. Craso error si atendemos a lo antes mencionado con respecto a que los vínculos con los países fronterizos, al menos sin ninguna duda en el 
espacio andino en su conjunto, se extendieron con vínculos estrechos $\mathrm{y}$, a veces más importantes que su integración al mercado nacional, hasta avanzadas las décadas de 1930 y 40.

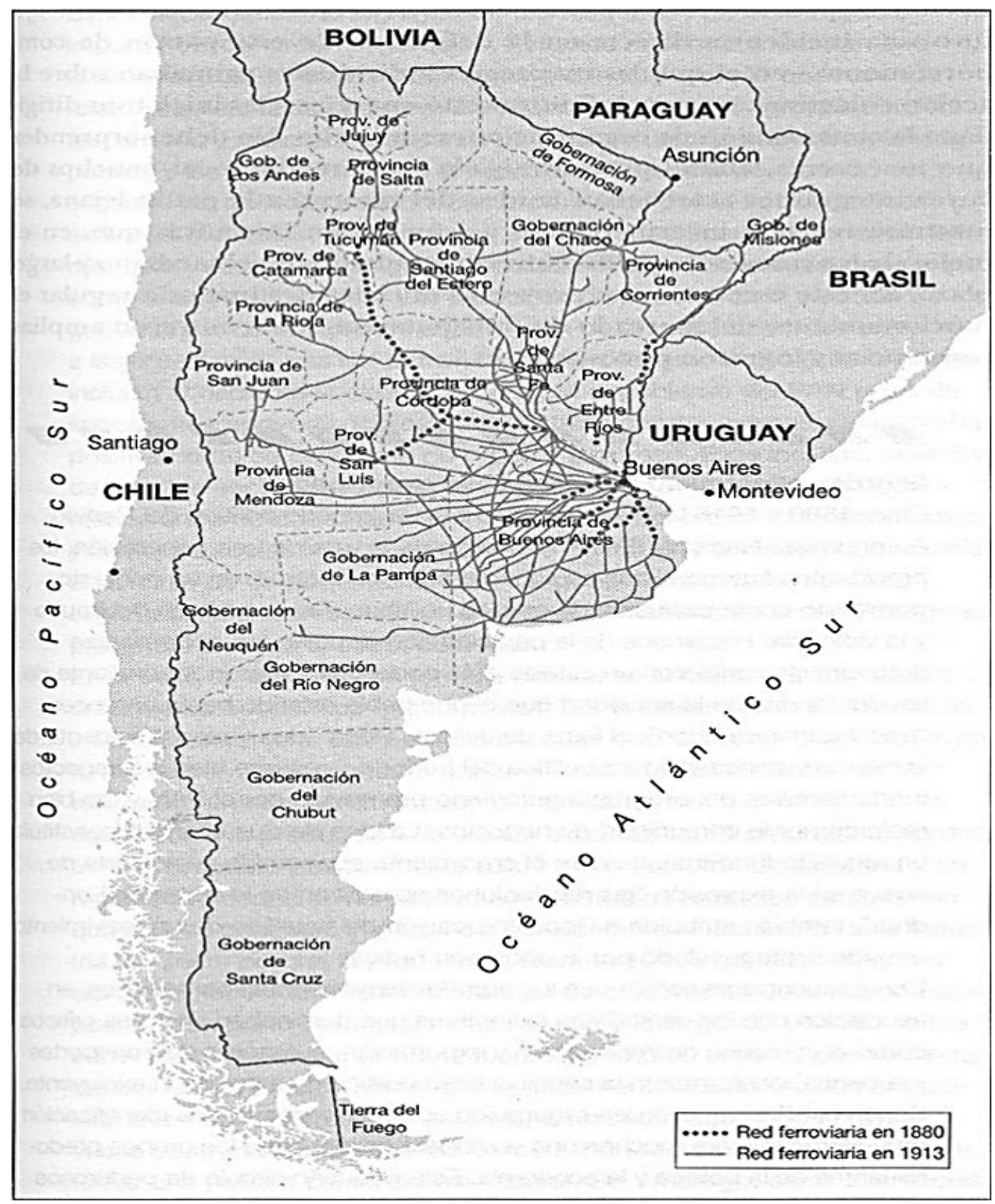

Fuente: reproducción del mapa que se utiliza frecuentemente en las aulas para desarrollar el tema.

\section{A manera de síntesis}

Como vemos entonces, los aportes complejos y variados que desde hace décadas vienen haciendo los estudios en perspectiva local y regional, distan mucho todavía de 
haber sido incorporados a diversas visiones generalizadoras y homogéneas de la historia nacional.

Con referencia a la historia patagónica, varios son los mitos que se corrigieron con las producciones de las últimas décadas que, necesariamente, deberían incorporarse en el proceso de enseñanza de la historia argentina Una de ellos tiene que ver con la existencia de una "frontera interna" que, cual límite físico, parecería separar al mundo indígena del hispano-criollo. Hoy son muchísimas las producciones que, desde la región misma y fuera de ella, revisan exhaustivamente esta idea -a tal punto que enumerarlos sin omisiones sería casi imposible-, mostrando que no solo el conflicto sino que también, y particularmente, el intercambio de bienes y personas, eran características propias de ese espacio fronterizo, en tanto que la organización político-económica de las sociedades indígenas poseía un alto grado de complejidad, transformando radicalmente la idea generalizada de grupos nómades dedicados exclusivamente al saqueo, la caza y la recolección.

Un segundo mito se vincula con la idea de que el límite entre los Estados nacionales argentino y chileno constituido por la cordillera de los Andes, funcionó como tal para las sociedades involucradas a partir de la conquista por las armas de los espacios indígenas. Hoy sabemos, como ya se dijera, que las relaciones de todo tipo entre las áreas andinas y el mercado chileno perduraron con idénticas formas, con viejos y nuevos actores, vinculados ahora a las formas capitalistas de producción, hasta avanzado el siglo XX.

Una Patagonia poblada exclusivamente desde el Atlántico es otra de las creencias generalizadas que quienes hacemos historia regional hemos revisado. Si bien es cierto que los territorios con puertos sobre el Atlántico se incorporaron rápidamente a una economía ovina en expansión, no lo es menos que las zonas andinas siguieron manteniendo, como ya adelantáramos, intercambios económicos y sociales en las áreas fronterizas, proveyendo a los mercados trasandinos de ganados, especialmente vacunos para el consumo interno o para la fabricación de suelas, tasajo, velas y jabón, que Chile exportaba por sus puertos hacia Europa y a otros países del Pacífico Sur como Perú y Ecuador. Esto se acompañaba con importantes flujos migratorios de población de ese origen que traspasaba permanentemente la cordillera en busca de tierras o mejores 
posibilidades ocupacionales, en tanto que eran comunes las inversiones chilenas de capital en superficies productivas del oriente cordillerano. ${ }^{14}$

La imagen de un Estado nacional tempranamente exitoso en su penetración en los espacios ganados a las comunidades indígenas que suele mostrar la historiografía tradicional, debe también revisarse a la luz de las nuevas investigaciones. Sin duda así lo fue en lo que hace a las formas de penetración coactiva o represiva, por usar la conocida caracterización de Oszlak (1982), pero para nada en lo referente a los aspectos materiales e ideológicos, donde la ausencia del Estado resulta evidente hasta las décadas de 1930 y 40 cuando, según ya adelantáramos, la preocupación por "argentinizar" la Patagonia se volvió esencial para los gobiernos nacionalistas que por entonces dominaban el escenario político nacional.

Esto indica, por de pronto, la necesidad de revisar las periodizaciones todavía vigentes en la historiografía nacional con respecto a considerar a los años 1880 como un hito fundamental en la conformación definitiva de un Estado nacional y, en consecuencia, de un mercado interno plenamente constituido, con lo cual se habrían cortado definitivamente los vínculos que distintas regiones del país mantenían con los espacios limítrofes. Nada más lejos de la realidad para las áreas andinas, no solo de la Patagonia, sino del conjunto nacional, marginales al proceso de integración del país al modelo agroexportador.

Esta y otras periodizaciones del pasado nacional son imágenes básicas que han arraigado en el sentido común de los argentinos y también, por qué no decirlo, en el de muchos educadores. Lo mismo ocurre con los límites territoriales que la construcción de ese mismo pasado nacional encierra. Nos referimos, particularmente, a la demostrada construcción de una historia encerrada en los contornos actuales del Estado nacional argentino. Llama la atención, no obstante, la notable supervivencia de estas mismas cuestiones en el ámbito educativo actual, según ha podido verse en los mapas adjuntos.

Esto amerita algunas reflexiones. No hay duda de que muchos autores pueden repetir estas versiones porque comulgan con esa interpretación de la historia nacional y de la geografía -o de la geopolítica, para ser más precisos- y con sus contenidos ideológicos. Pero, en otros casos, resulta absolutamente dudoso que se trate de esos motivos. Creo que hay mucho de ingenuidad en los historiadores que usamos los mapas e imágenes con un sentido absolutamente ilustrativo, sin detenernos a analizar los

\footnotetext{
${ }^{14}$ A este respecto, pueden verse los distintos capítulos incluidos en Blanco (2018)
} 
preconceptos que esos elementos contienen. Tal vez cabría recuperar, para estos casos, la noción de "saber olvidado" de Max Scheler, es decir, lo que queda en el fondo de nuestra conciencia una vez que olvidamos los contenidos específicos que aquellas nociones portaban (ROMERO, 2004, p.18).

Pero, para no quedarnos solamente con los cambios que la producción regional patagónica puede aportar a una historiografía nacional más compleja, cabe mencionar el reciente esfuerzo conjunto que realizáramos con una colega de la Universidad Nacional de Rosario, con quien hemos publicado una Historia Argentina en perspectiva local y regional en tres volúmenes, donde más de cincuenta autores dan a conocer sus producciones. Como allí se dice, en la presentación general de la obra:

E1 conjunto no pretende ser ni una miscelánea ni una síntesis, sino un pase cuadro a cuadro de una secuencia de investigaciones sobre varios de los tópicos que han mantenido una línea de trabajo y una tradición durante las últimas tres décadas [...]

Treinta años de producción escrita, marcados por la recuperación democrática de la universidad argentina en 1983 y la proyección de los organismos públicos de investigación, que han consolidado un corpus en el marco de un escenario historiográfico novedoso dentro del campo, quizás el más prolífico que hayamos observado [...] También se distancia de la idea de colección como reunión de elementos significativos, ya que la perspectiva transversal propuesta desde los ejes seleccionados prioriza la problematización por sobre el proceso [...] La compilación pone en cuestión las formas de ver el "hecho nacional" como emergente fundamental, a la vez que resiste a su influencia. Desenfocar el análisis de la retórica de lo nacional, no para marginarla, sino para incluirla como una más en un escenario compartido donde asisten otros protagonistas, conlleva un ejercicio de puesta en escena de investigaciones mostrando balances y líneas de fuerza que alimentan nuestro campo de estudio [...] Se eligió una opción que no es la síntesis, la colección o el manual. Esta compilación es una composición coral que muestra la madurez de la perspectiva regional y local en la historiografía argentina y que, aun a riesgo de dispersar temáticamente y de contraer alcances cronológicos (problemas lógicos de una compilación), tiene la gran virtud de dinamizar el nivel de reflexión y de exponer un estado de la cuestión sugerente sobre nuestra producción científica actual. En ese sentido, esta obra, "es el paso de una historia nacional a muchas historias argentinas" (BANDIERI y FERNÁNDEZ, 2017).

Reafirmando lo dicho, como sostienen Scalona y Fernández, se deberán aumentar los esfuerzos por "acentuar la potencialidad analítica de la historia de matriz regional y local; corriéndola de su lugar de simple recurso didáctico y enfatizando su carácter explicativo, dando cuenta de que los estudios regionales y locales no son referentes 
anecdóticos de un pasado más remoto o más cercano, ni tampoco son fruto de investigaciones parciales que no disponen de un contexto de comprensión significativo dentro del proceso educativo" (SCALONA y FERNÁNDEZ, 2004, p.104; SCALONA, 2005). Pero para ello, y coincidiendo con las mismas autoras, se necesita un especial compromiso de los docentes de los distintos niveles de enseñanza por actualizarse de forma permanente, tanto en los aspectos conceptuales como empíricos, así como para interactuar en forma conjunta y complementaria, a los efectos de que "la Historia investigada y la Historia enseñada" sean la misma Historia.

\section{Referencias}

BANDIERI, Susana (comp.). Cruzando la cordillera... La frontera argentino-chilena como espacio social. Siglos XIX y XX. Neuquén, CEHIR-UNCo, 2001.

BANDIERI, Susana. Cuando crear una identidad nacional en los territorios patagónicos fue prioritário. Revista Pilquen. Sección Ciencias Sociales, Revista Digitalizada, Año XI, n ${ }^{\circ}$ 11, Viedma, Centro Universitario Zona Atlántica - CURZA-, UNCo, 2009. (http://www.revistapilquen.com.ar/SumarioCS11.htm)

BANDIERI, Susana. La frontera argentino-chilena como espacio social en la Patagonia: balance de una historiografía renovada. En Núñez, A., Sánchez, R. y Arenas, F. (ed.) Fronteras en movimiento e imaginarios geográficos. La Cordillera de los Andes como especialidad socio-cultura. Santiago de Chile: Instituto de Geografía de la Universidad Católica de Chile, Serie Geolibros, RIL Editores, 2013a., p.67-88.

BANDIERI, Susana. La noción de "espacio económico". En Carlos Sempat Assadourian y sus posibilidades de uso en historias regionales de lugares y tiempos diferentes". Revista Estudios del ISHiR, Año 2, No 4, 2013b. Unidad Ejecutora en Red ISHiR - CONICET, Argentina (http://www.revista.ishirconicet.gov.ar/index.php/revistaISHIR

BANDIERI, Susana. La perspectiva regional y local. Un camino posible para una historia argentina renovada. En Ernesto Bohoslavsky, coord., "Debates y conflictos de la historia regional en la Argentina actual", Quinto Sol, Vol. 22, $\mathrm{N}^{\mathrm{O}} 3$, septiembrediciembre, 2018a. (DOI: http://dx.doi.org/10.19137/qs.v22i3.3337).

BANDIERI, Susana. Haciendo historia regional en la Argentina. En Dossie Politica Locais, Centralidades e Regiões: Brasil, Chile e Argentina. Revista TEL, Tempo, Espaço e Linguagem, v. 9, $\mathrm{n}^{\circ}$ 1, jan-jun, 2018b. Universidade Estadual do Centro Oeste (UNICENTRO), Campus de Irati, Brasil. (http://www.revistas2.uepg.br/index.php/tel/index)

BANDIERI, Susana. "Argentinizar a los patagónicos": la preocupación del Estado argentino por generar una identidad nacional en la Patagonia. En Claudia Hammerschmidt y Laura Pollastri, Eds., Patagonia plural. Identidades híbridas e intersecciones epistemológicas en una región transfronteriza. London-Deutschland, INOLAS Publishers LTD, 2018b. 
BANDIERI, Susana, VARELA, Gladys y BLANCO, Graciela, dir. Hecho en Patagonia. La historia en perspectiva regional. Neuquén, CEHIR-UNCo., EDUCOEditorial Universitaria-, 2006.

BANDIERI, Susana y BLANCO, Graciela, coord. Patagonia Total, Antártida e Islas Malvinas, . Enciclopedia Educativa. Primera Parte Historias de la Patagonia. Sociedades y espacios en el tempo. Colombia, Barcel-Baires, Ediciones-ALFA Centro Literario, 2007.

BANDIERI, Susana y FERNÁNDEZ, Sandra, eds. La historia argentina en perspectiva local y regional. Nuevas miradas para viejos problemas. Tomos 1,2 y 3 , Buenos Aires, Editorial Teseo, 2017.

BLANCO, Graciela, edit. La tierra pública en la Patagonia. Normas, usos, actores sociales y tramas relacionales. Rosario, Prohistoria Ediciones, 2018.

BLANCO, Graciela, GENTILE, Beatriz y QUINTAR, Juan. Neuquén, 40 años de vida institucional 1958-1998. Neuquén, CEHIR-UNCo./COPADE, 1998.

FERNÁNDEZ, Sandra, comp. Más allá del territorio. La historia regional y local como problema. Discusiones, balances y proyecciones. Rosario, Prohistoria Ediciones, 2007.

FERNANDEZ, Sandra. Los mundos ocultos. Los estudios regionales en la enseñanza de la Historia en la Argentina. História Unisinos. 13(1):35-42, 2009. Janeiro/Abril (doi: $\underline{10.4013 / \text { htu.2009.131.03) }}$

FERNÁNDEZ, Sandra y DALLA CORTE, Gabriela, comp. Lugares para la historia. Espacio, historian regional e historian local en los estudios contemporáneos. Rosario, Universidad Nacional de Rosario Editora, 2001.

MÉNDEZ, Laura. Las efemérides en el aula. Aportes teóricos y propuestas didácticas inovadoras. Buenos Aires-México, Ediciones Novedades Educativas, 2005.

MÉNDEZ, Laura e IWANOW, Wladimiro. Bariloche: Las caras del passado. Neuquén, Manuscrito Libros, 2001.

MÉNDEZ, Laura y DIAZ, Víctor. Clarita del Sur. Neuquén, Ediciones Pido la Palabra, 2007.

OSZLAK, Oscar. La formación del Estado Argentino. Buenos Aires, Ed. de Belgrano, 1982.

ROMERO, Luis Alberto (coord.). La Argentina en la escuela. La idea de Nación en los textos escolares. Buenos Aires, Siglo XXI, 2004.

SCALONA, Elvira. La historia local como contenido de enseñanza. En Fernández, S. (comp.). Más allá del territorio: la historia regional y local como problema: discusiones, balances y proyecciones. Rosario, Prohistoria Ediciones, 2007.

SCALONA, E. y FERNÁNDEZ, Sandra. La historia regional en el nivel polimodal: balance y perspectivas. Revista Reseñas, 2:81-104, 2004.

WINDERBAUM, Silvio (1999) NEUQUÉN para chicos y para grandes. Neuquén, Ediciones Pido la Palabra.

SEMPAT ASSADOURIAN, Carlos. El sistema de la economía colonial. Mercado interno, regiones y espacio económico. Lima, Instituto de Estudios Peruanos, 1982. 
WINDERBAUM, Silvio. NEUQUÉN preguntas para entender la ciudad. Neuquén, Ediciones Pido la Palabra, 2004.

WINDERBAUM, Silvio. Para pensar y entender RÍO NEGRO. Neuquén, Ediciones Pido la Palabra, 2006.

WINDERBAUM, Silvio. PATAGONIA. Temas y problemas. Neuquén, Ediciones Pido la Palabra, 2015.

WINDERBAUM, Silvio. RÍO NEGRO. temas y problemas. Neuquén, Ediciones Pido la Palabra, 2018.

Recebido em: 11 de maio de 2019.

Aprovado em: 28 de junho de 2019. 